\title{
Conserved variable analysis of the marine boundary layer and air-sea exchange processes using BOBMEX-Pilot data sets
}

\author{
N V SAm, U C Mohanty and A N V SATyanarayana \\ Centre for Atmospheric Sciences, Indian Institute of Technology, Delhi, New Delhi, India
}

\begin{abstract}
The present study is based on the observed features of the MBL (Marine Boundary Layer) during the Bay of Bengal and Monsoon Experiment (BOBMEX) - Pilot phase. Conserved Variable Analysis (CVA) of the conserved variables such as potential temperature, virtual potential temperature, equivalent potential temperature, saturation equivalent potential temperature and specific humidity were carried out at every point of upper air observation obtained on board ORV Sagar Kanya. The values are estimated up to a maximum of $4 \mathrm{~km}$ to cover the boundary layer. The Marine Boundary Layer Height is estimated from the conserved thermodynamic profiles. During the disturbed period when the convective activity is observed, the deeper boundary layers show double mixing line structures. An attempt is also made to study the oceanic heat budget using empirical models. The estimated short-wave radiation flux compared well with the observations.
\end{abstract}

\section{Introduction}

The Bay of Bengal and Monsoon Experiment (BOBMEX) is a cooperative field experiment under the Indian Climate Research Program (ICRP). The main objective of BOBMEX is to study the air-sea interaction and the associated characteristics of the Marine Boundary Layer (MBL) in the Bay of Bengal during the monsoon. This regional scale phenomenon along with the low-level temperature inversion and crossequatorial fluxes play a significant role in the maintenance of the monsoon activity.

In an effort to understand the MBL over the oceans and its role in regulating the transport of energy and moisture upward into the atmosphere from the surface and its influence on the atmospheric convection, various field experiments were carried out in the past. The International Indian Ocean Expedition (IIOE), during 1963-65, paved the way to study the thermal and kinematic features of the monsoon flow over the Arabian Sea and the adjoining west Indian Ocean. During this expedition, Bunker (1965), made few boundary layer measurements and discussed the characteristics of MBL. After the IIOE, Indo-Soviet Monsoon experiment (ISMEX), 1973, the Monsoon experiment (MONEX), 1979 were carried out. Jambunathan and Ramamurty (1975), studied the air-sea temperature distribution over the west Indian Ocean. Ramanathan (1978), assessed the bulk layer variation over the Arabian Sea along $10^{\circ} \mathrm{N}$ and along the equator. Pant (1978) discussed the vertical structure of the MBL in the west Indian Ocean using ISMEX data sets. Mohanty and Dube (1981), studied the statistical structure of the meteorological parameters over the Bay of Bengal. Kondo and Mirua (1985), presented the computation of surface MBL fluxes at the air-sea interface over the western Pacific during MONEX-79. All these studies illustrate, that the airsea exchange processes play a dominant role in the energy transport from ocean surface to the atmosphere, which in turn, act as a feed back mechanism for convection and circulation in the tropics.

It is known that the global climate depends on the transport mentioned earlier and increasing attention is given to the parameterization of the Convective Boundary Layer (CBL) in global forecast models (Betts and Miller 1986; Betts 1986; Albrecht et al 1986). The aim of this paper is to study the thermal structure of the MBL, especially the CBL using the Conserved Variable Analysis (CVA), an approach suggested by Betts

Keywords. Marine Boundary Layer Height (MBLH); Convective Boundary Layer (CBL); Conserved Variable Analysis (CVA).

Proc. Indian Acad. Sci. (Earth Planet. Sci.), 109, No. 2, June 2000, pp. 305-314

(C) Printed in India 


\section{PILOT BOBMEX CRUISE TRACK \\ SAGAR KANYA CRUISE NO: SK $138 \mathrm{C}$ \\ PERIOD: 23-10-98 TO 11-11-98 (GOA - TUTICORIN)}

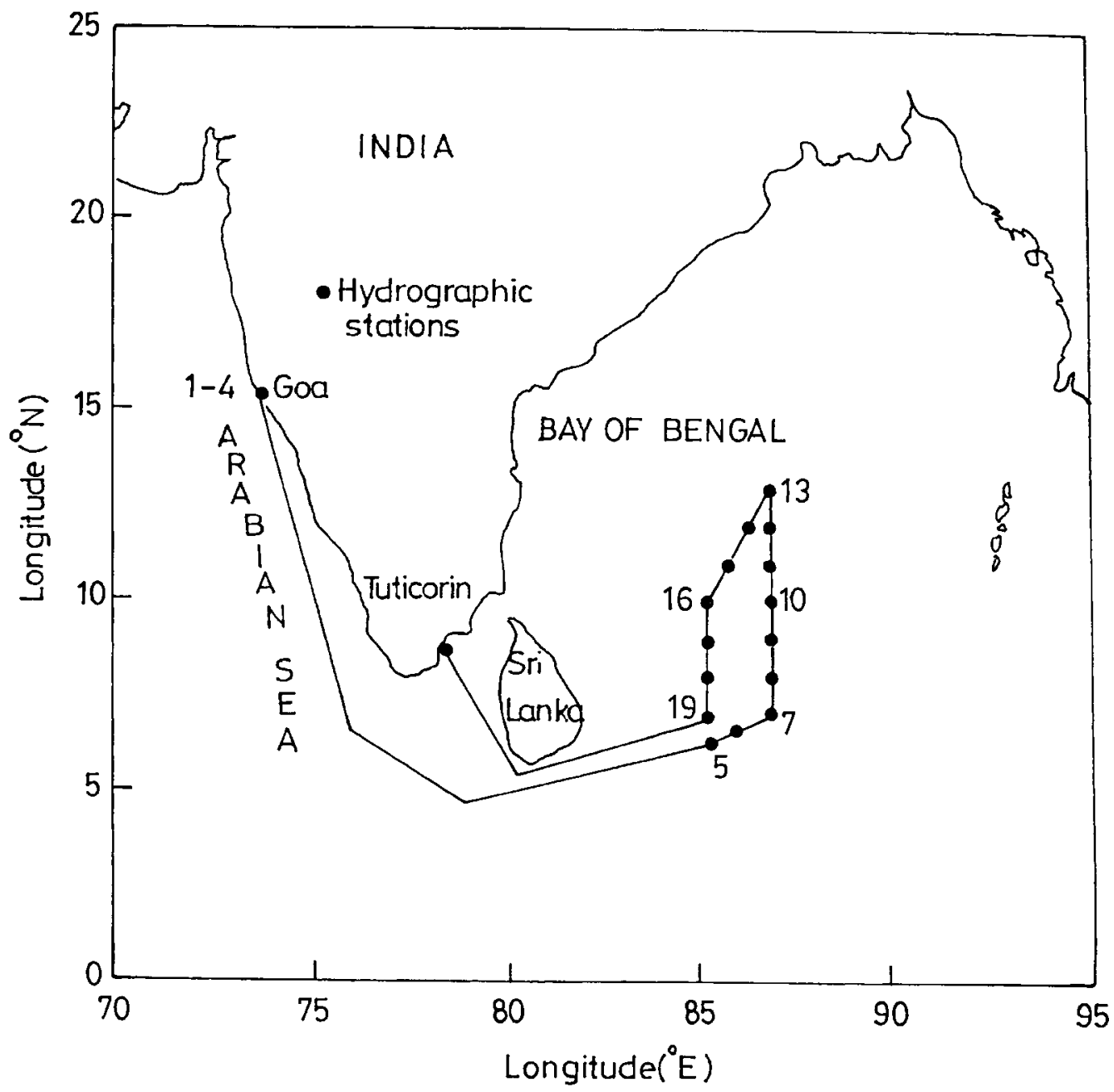

Figure 1. Cruise track of ORV Sagar Kanya during BOBMEX Pilot experiment.

(1985). An attempt is also made to study the oceanic heat budget using the surface synoptic meteorological observations obtained during the experiment, in order to examine the possible linkage between the net oceanic heat budget and the CBL structure.

\section{Data}

Surface meteorological parameters such as wind speed, wind direction, sea surface temperature (SST), drybulb and wet-bulb temperature and cloud cover, collected at every 3-hour interval, on board ORV Sagar Kanya from 23rd October - 8th November 1998 are used for the present study. During the cruise three stationary locations were identified for time series observations

- at $\left(7^{\circ} \mathrm{N}, 87^{\circ} \mathrm{E}\right), 30$ th -31 st October 1998 ,

- at $\left(10^{\circ} \mathrm{N}, 87^{\circ} \mathrm{E}\right), 2 \mathrm{nd}-3 \mathrm{rd}$ November 1998 and

- at $\left(13^{\circ} \mathrm{N}, 87^{\circ} \mathrm{E}\right)$ on 5 th November 1998.
The three sites were chosen anticipating specific synoptic activity such as convectively active and convectively suppressed conditions. The ship sailed back thereafter and reached Tuticorin on 12th November 1998. The time series observations were used to compute the oceanic heat budget parameters. In addition to the observed surface parameters, upper air observations of temperature and relative humidity, obtained by launching radiosonde and low-level sonde (India Meteorological Department) and minisonde (Indian Institute of Science and Space Physical Laboratory) are used for the CVA. The cruise track is shown in figure 1.

\section{Synoptic conditions in the Bay of Bengal}

An initial disturbance, which is seen to be innocuous in the satellite imagery on $23 \mathrm{rd}$ October $\left(8^{\circ} \mathrm{N}, 101.5^{\circ} \mathrm{E}\right)$ 
1998 seemed to have a tropospheric cyclonic circulation with associated wind speed of 10-15 knots at $850 \mathrm{mb}$ (Kalsi 1999). NCMRWF analysis showed that this circulation moved westwards and was more marked on 26th October 1998, with wind speeds in the lower tropospheric levels, of the order of 15-20 knots. Later the low level structure got deformed and was found to be oriented in the northeast direction apparently in response to the trough in the mid and upper tropospheric westerlies over Pakistan/Afghanistan region on 29th October 1998.
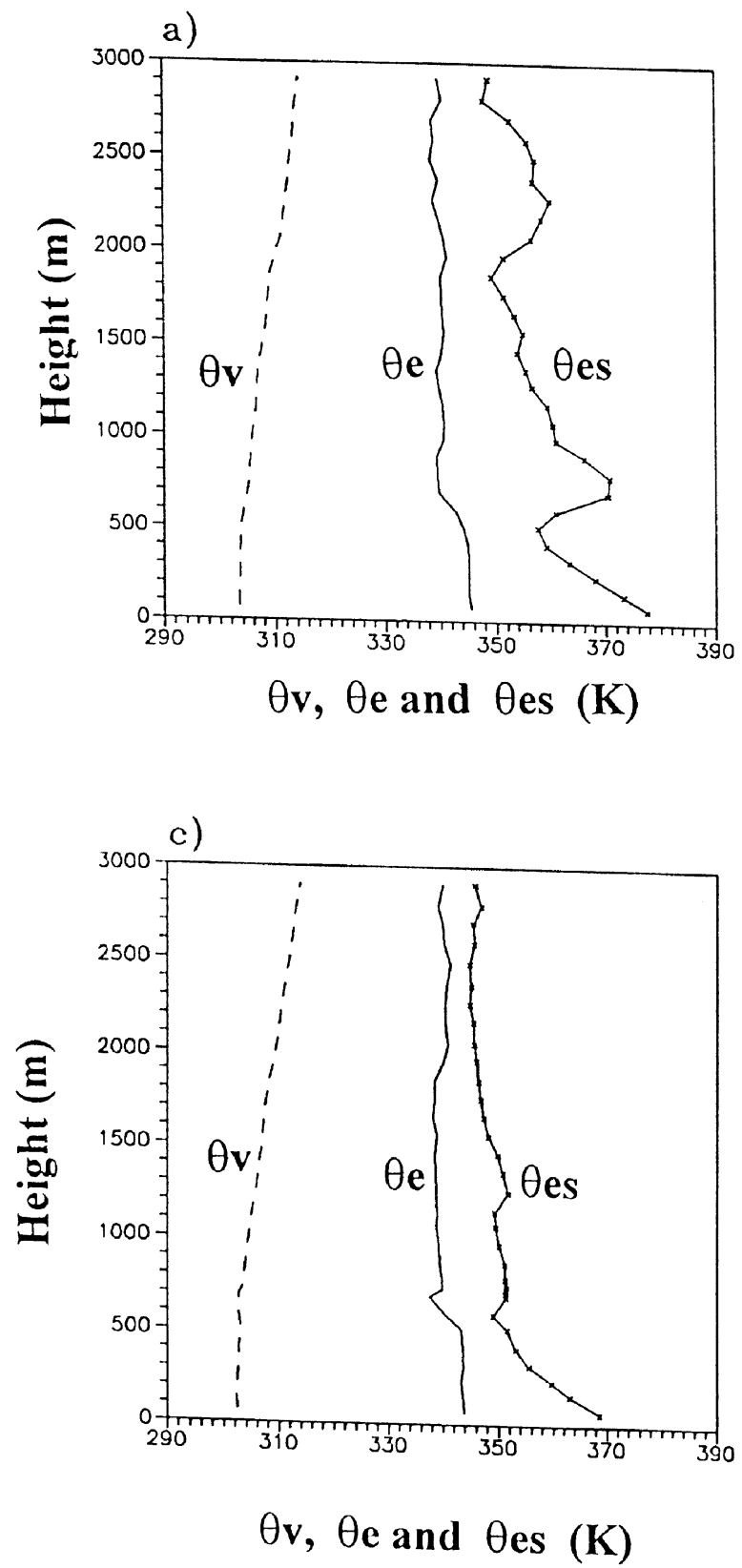

However, on 1st November 1998 when the ship was positioned at $\left(7^{\circ} \mathrm{N}, 87^{\circ} \mathrm{E}\right)$, classified as the disturbed period, a shear zone was observed over the south Bay of Bengal and throughout the day it had rained. From 3rd - 5th November 1998, the weather is noticed to be relatively calm. Two specific periods were classified for the CVA viz.

- the disturbed period, 30 th -31 st October $\left(7^{\circ} \mathrm{N}, 87^{\circ} \mathrm{E}\right)$ and 2nd November $\left(10^{\circ} \mathrm{N}, 87^{\circ} \mathrm{E}\right) 1998$

- the undisturbed period, 3 rd November $\left(10^{\circ} \mathrm{N}, 87^{\circ} \mathrm{E}\right)$ and 5th November $\left(13^{\circ} \mathrm{N}, 87^{\circ} \mathrm{E}\right)$.
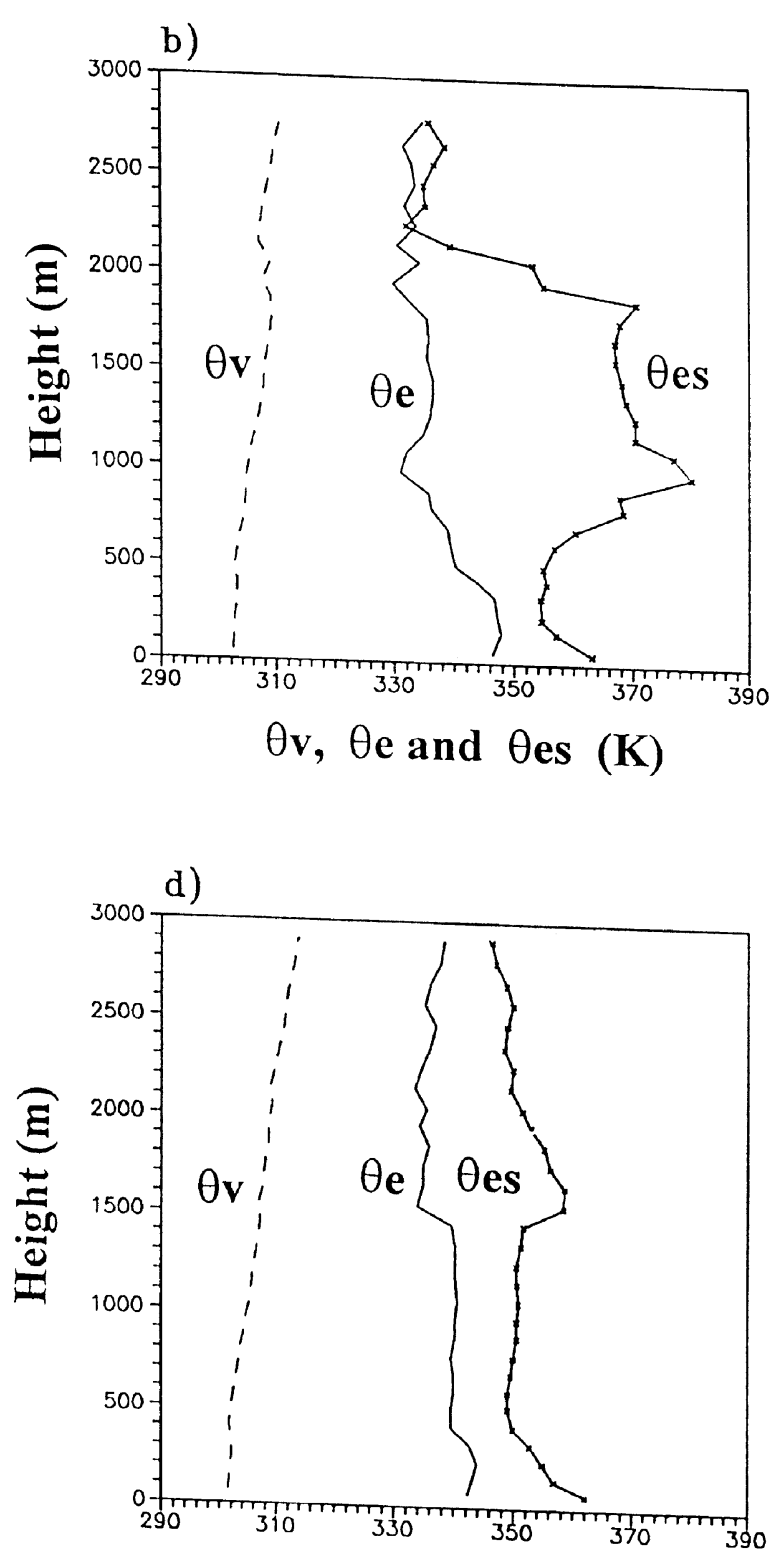

\section{$\theta \mathbf{v}, \theta \mathbf{e}$ and $\theta \mathbf{e s}(\mathbf{K})$}

Figure 2. $\quad \theta_{v}, \theta_{e}$ and $\theta_{e s}$ during the disturbed period (a) 31-10-1998, 0700 IST; (b) 31-10-1998, 1545 IST; (c) 01-11-1998, 1430 IST; (d) 02-11-1998, 2100 IST. 


\section{Methodology and analysis procedure}

\subsection{Conserved Variable Analysis}

Betts and Albrecht (1987) gave an idealized illustration of CVA depicting the importance of the Conserved Variable Diagrams. A schematic mixing line (Betts 1982) is shown between Saturation Points (SPs) of the mixed sub-cloud layer and the CBL top on a $\left(\theta_{e}, q_{T}\right)$ diagram. The $q_{T}$ (specific humidity) axis for the unsaturated air has been reversed so that a sounding data plotted on this diagram resembles the more familiar $\left(\theta_{e}, p\right)$ plot. In the absence of irreversible diabatic processes, conserved variables are represented on both the axes. $\theta_{e}$ (equivalent potential temperature) or $q_{T}$ is not changed during condensation process, whereas, the precipitating process moves the parcel points to lower $q_{T}$ at constant $\theta_{e}$ (and the reverse for the evaporation of falling precipitation). The radiative process does not change $q_{T}$, but radiative cooling moves SPs to lower $\theta_{e}$ at constant $q_{T}$. Mixing lines are straight lines and advective processes do not move the parcel points at all. The thermodynamic changes represented by the triangular path
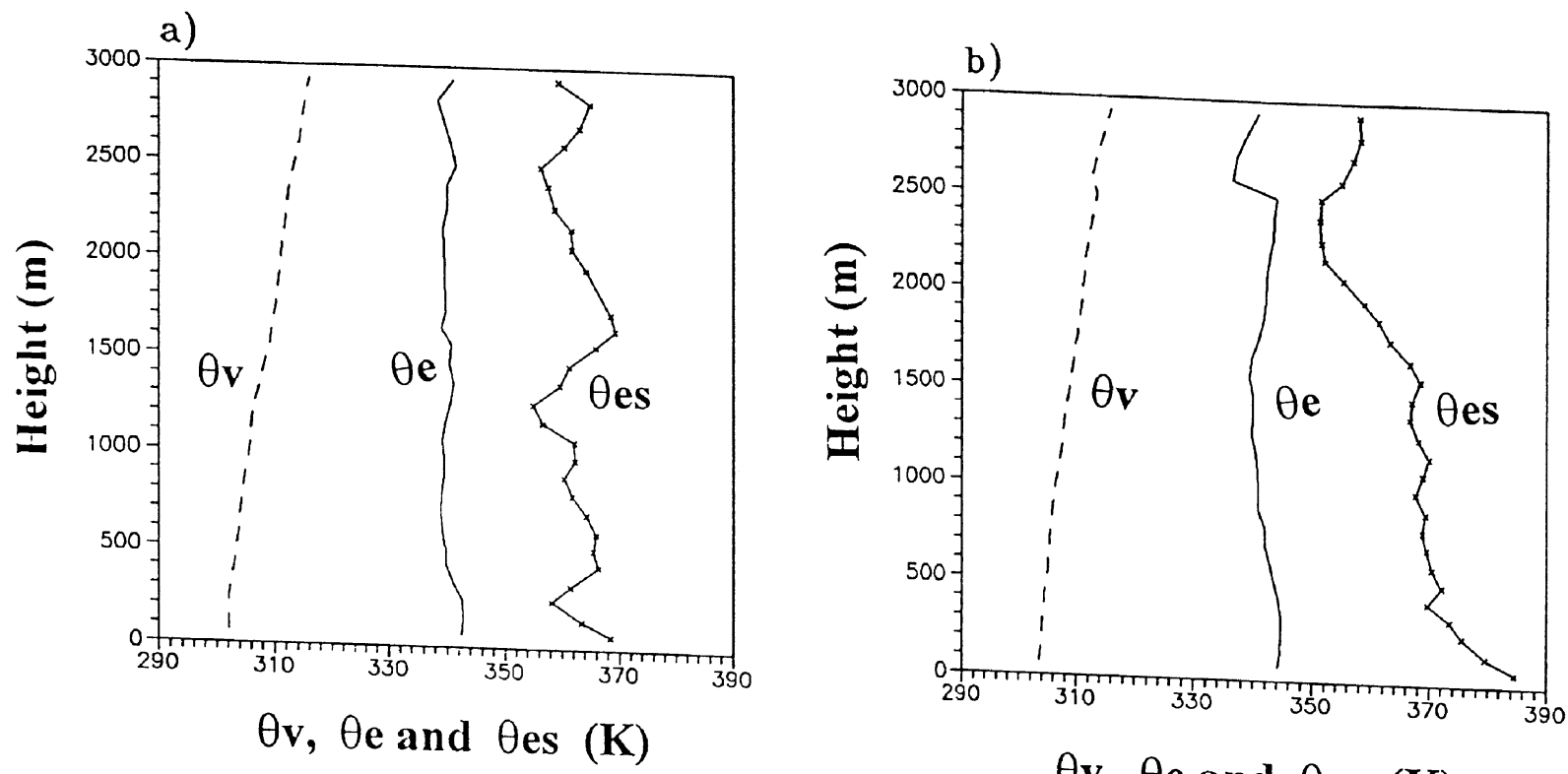

$\theta \mathbf{v}, \theta \mathbf{e}$ and $\theta \mathbf{e s}(\mathbf{K})$
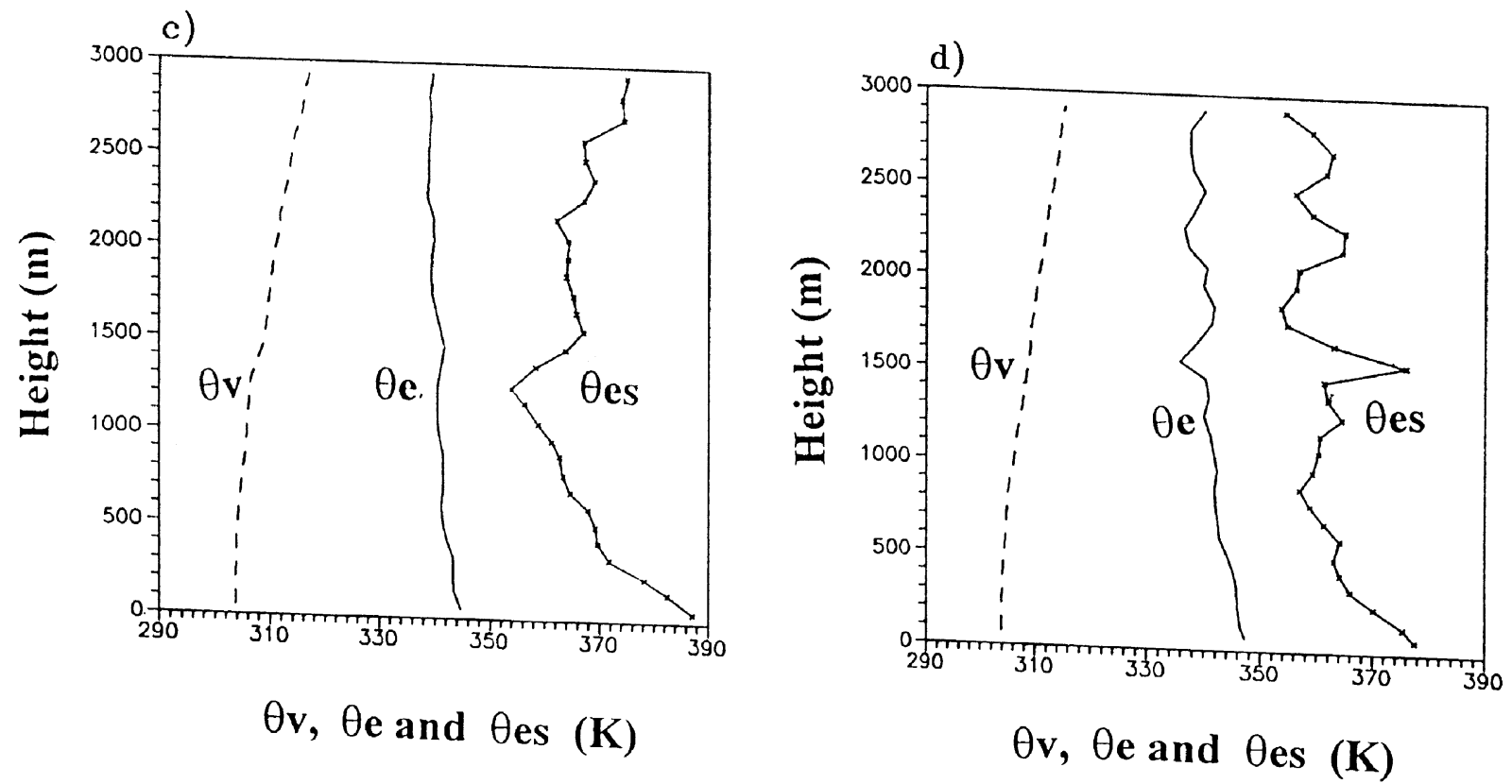

Figure 3. $\theta_{v}, \theta_{e}$ and $\theta_{e s}$ during the undisturbed period (a) 03-11-1998, 0700 IST; (b) 03-11-1998, 1445 IST; (c) 05-11-1998, 0615 IST; (d) 05-11-1998, 2000 IST. 
shows precipitation in the ascending deep convective branch of the tropical circulation which moves the parcel from the sub-cloud layer to lower $q_{T}$, at constant $\theta_{e}$. Radiative cooling in the subsiding branch lowers $\theta_{e}$ at constant $q_{T}$. The air with the lowest $\theta_{e}$ sinks into the CBL and its SPs move down the mixing line as it is mixed with air from below on its final mean descent back into the sub-cloud layer.

\subsection{Marine Boundary Layer Height (MBLH)}

Vertical profiles of virtual potential temperature $\left(\theta_{v}\right)$, equivalent potential temperature $\left(\theta_{e}\right)$ and saturation equivalent potential temperature $\left(\theta_{e s}\right)$ are drawn to estimate the MBLH. The MBLH is marked by minimum $\theta_{e}$ and maximum $\theta_{e s}$. This criterion (usage of $\theta_{e}$ and $\theta_{e s}$ ) was used, because variables such as potential temperature and water-vapour mixing ratio are not conserved in a cloud, because of latent heat release/ absorption and condensation/evaporation processes. MBL and CBL are synonymously used as the cases considered were differentiated on the basis of convection (active or suppressed convection). MBLH is therefore considered to be a mixed layer dominated by buoyant turbulence, which is also the Convective Boundary Layer Height (CBLH). Plots of $p^{*}$ (saturation level pressure) and $P\left(=p^{*}-p\right)$ against pressure $(p)$ were drawn, where the negative values of $P$ are related to the layer of sub-saturation. This MBL height can also be estimated by marking the minimum of $P$ at the inversion top.

\subsection{Static stability analysis}

In the tropical atmosphere, condensation processes are very important. Therefore, it is not enough, to consider only dry adiabatic vertical displacements, as in the process of vertical displacement the parcel is likely to reach the condensation level. Above this level, the parcel cools at the saturation adiabatic lapse rate. The Saturation Static Energy $\left(S_{e s}\right)$, is calculated using the expression:

$$
S_{\text {es }}=C_{p} T+g z+L q_{\mathrm{sat}},
$$

where, $C_{p}$ is the specific heat for moisture air, $T$ is the temperature, $g$ is the acceleration due to gravity, $z$ is the height above m.s.l., $L$ is the latent heat of vaporization and $q_{\text {sat }}$ is the saturation specific humidity. The partial change in $S_{e s}$ with respect to $z$, i.e. $\partial S_{e s} / \partial z$ determines the moist static stability. Stable atmosphere is characterised by the positive gradient of $\partial S_{e s} / \partial z$.

\subsection{Oceanic heat budget}

To study air-sea exchange processes over the Indian Ocean, the radiative fluxes (short and long-wave ra- diation) and the turbulent heat fluxes (sensible and latent heat fluxes) were computed using semi-empirical models and bulk aerodynamic method respectively. The oceanic heat budget equation (in $\mathrm{Wm}^{-2}$ ) can be written as:

$$
Q_{N}=Q_{S}-Q_{B}-Q_{H}-Q_{E}
$$

where $Q_{N}$ is the net heat loss/gain, $Q_{S}$ is the shortwave radiative flux, $Q_{B}$ is the long-wave radiative flux, $Q_{H}$ is the sensible heat flux and $Q_{E}$ is the latent heat flux. Here, the heat transported by ocean currents (advection of heat) is neglected because in short time scales, it is not appreciable. The detail of the estimation of the parameters on the right-hand side of the equation is computed by the methods suggested by Mohanty and Mohan Kumar (1990).

The short-wave radiation flux reaching the ocean surface is obtained using semi-empirical expression given by Atwater and Ball (1981), whereas the effective long-wave radiation flux is computed using the expression given by Girduk and Malevaski-Holekyich (1973). The transfer coefficients were computed as a function of both atmospheric stability and wind speed as suggested by Mohanty and Mohan Kumar (1998).

\section{Results and discussion}

Figure 2(a-d) represents the $\theta_{v}, \theta_{e}$, and $\theta_{e s}$ profiles during the disturbed period. From these profiles the MBLH is estimated, which is characterised by a maximum in $\theta_{e s}$ and a minimum in $\theta_{e}$. The typical threelayer structure (sub-cloud, cloud and inversion layers) of the CBL (Betts and Albrecht 1987) is quite apparent in the present data sets too. The relative high humidity inside in the cloud layer (distinctly moist) is unstable in $\theta_{e s}$. Figures 2(a), 2(b) and 2(d) give a distinct estimate of the MBLH as the $\theta_{e s}$ and $\theta_{e}$ profiles show marked increase and decrease respectively at the inversion top. $\theta_{v}$ profiles are not used to estimate the MBLH as $\theta_{e s}$ and $\theta_{e}$ profiles are more

Table 1. Marine boundary layer height during disturbed and undisturbed period.

\begin{tabular}{lcc}
\hline Date & Time (IST) & MBLH (disturbed period) $(\mathrm{m})$ \\
\hline $31-10-1998$ & 0700 & 800 \\
$31-10-1998$ & 1545 & 1000 \\
$01-11-1998$ & 1430 & 1300 \\
$02-11-1998$ & 2100 & 1700
\end{tabular}

\begin{tabular}{lcc}
\hline Date & Time (IST) & MBLH (undisturbed period) $(\mathrm{m})$ \\
\hline $03-11-1998$ & 0700 & 425 \\
$03-11-1998$ & 1445 & 507 \\
$05-11-1998$ & 0615 & 1250 \\
$05-11-1998$ & 2000 & 1555 \\
\hline
\end{tabular}



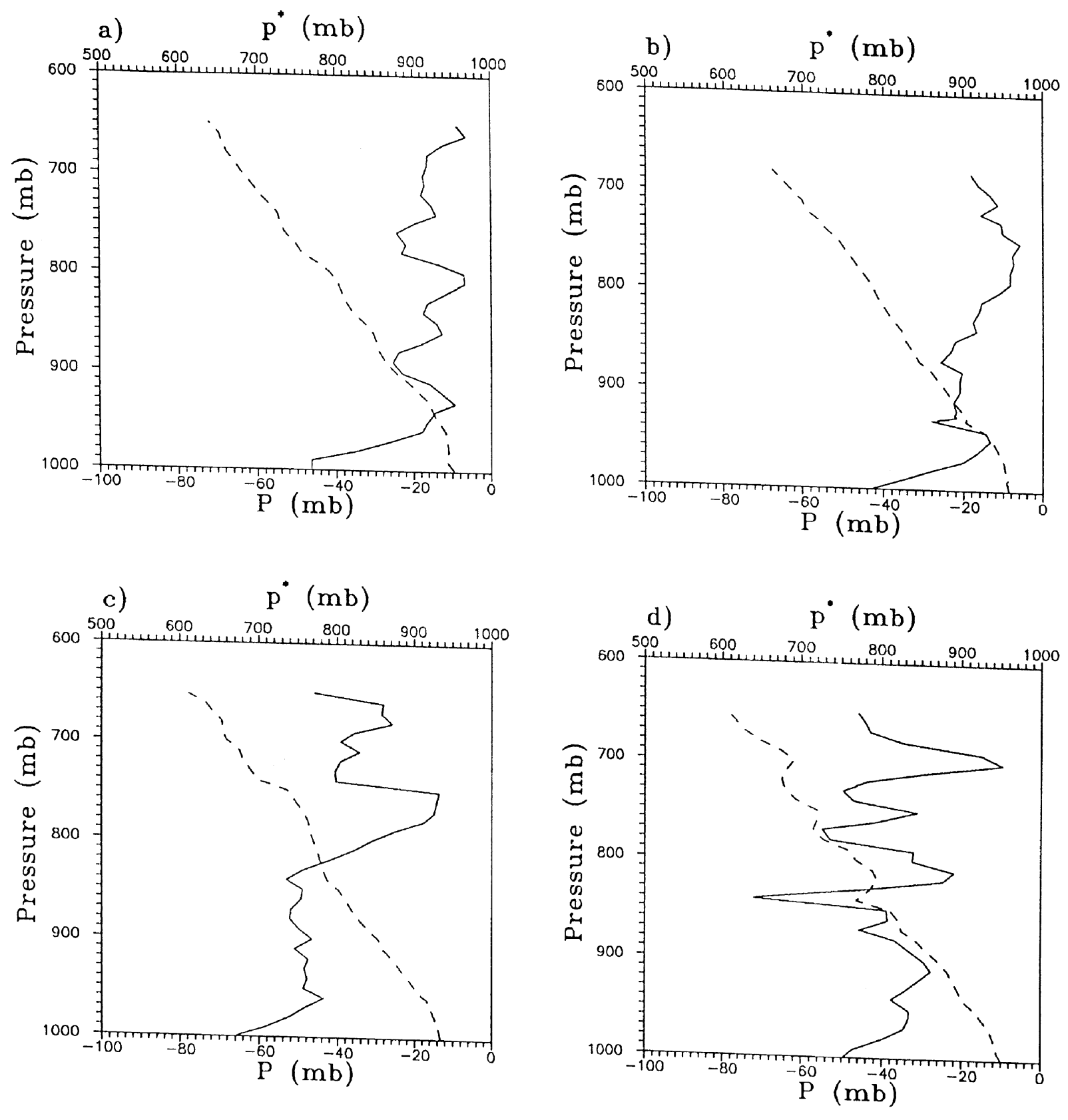

$$
\begin{aligned}
& -p=\left(p^{*}-p\right) \\
& --p^{*} \text { (Saturatuion Level Pressure) }
\end{aligned}
$$

Figure 4. Plot of $p^{*}$ and $P=\left(p^{*}-p\right)$ against pressure. During disturbed period (a) 01-11-98, 0700 IST; (b) 01-11-98, 1430 IST. During undisturbed period (c) 03-11-98. 1445 IST; (d) 05-11-98, 2000 IST.

distinct and representative. On 2nd November 1998, (figure 2d) the MBLH is observed to attain a maximum of $1700 \mathrm{~m}$. This is due to active convection when deeper boundary layers are formed. Continuous rain is also observed during this period. During the undisturbed period, figure $3(\mathrm{a}-\mathrm{d})$, the estimated MBLH is found to be less, when compared to the disturbed period. In figure $3(\mathrm{~d})$, marked maximum and minimum in $\theta_{e s}$ and $\theta_{e}$ profiles, respectively, is noticed, while such distinct features are not observed in figure $3(\mathrm{a}-\mathrm{c})$. The estimated MBLH is given in table 1 . The average MBLH during the disturbed and undisturbed period is found to be $1200 \mathrm{~m}$ and $934 \mathrm{~m}$ respectively. Figure $4(\mathrm{a}-\mathrm{d})$ shows $p^{*}$ and $P=\left(p^{*}-p\right)$ against pressure, where $p^{*}$ is saturation level pressure. In the absence of radiation and mixing processes, the $p^{*}$ of a parcel is unchanged by vertical (dry or moist adiabatic) motion, so that, if air above the CBL 

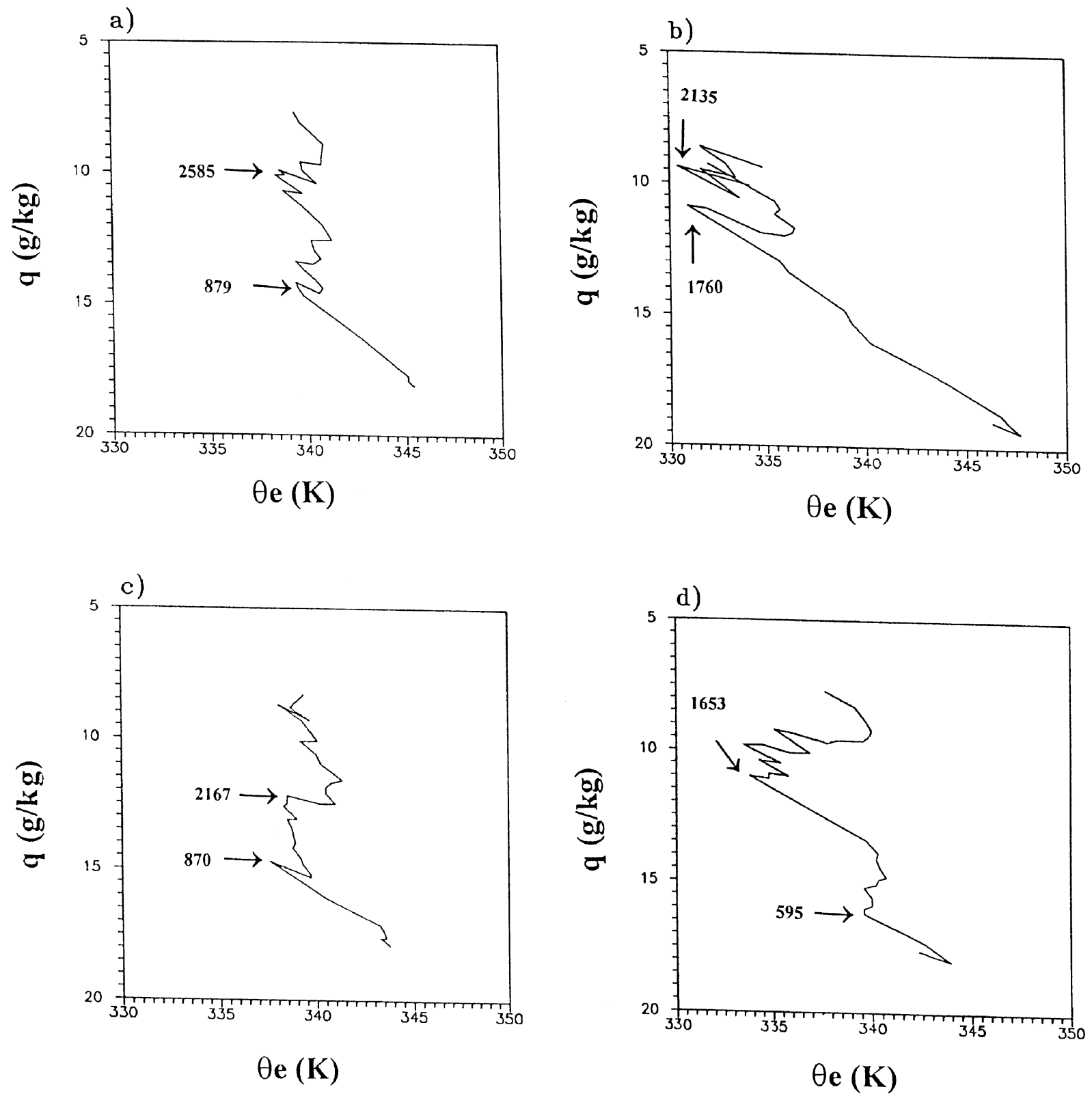

Figure 5. Plot of $\theta_{e}$ against $q$. During disturbed period (a) 31-10-1998, 0700 IST; (b) 31-10-1998, 1545 IST; (c) 01-11-1998. 1430 IST; (d) 02-11-98, 1500 IST. ( $\rightarrow$ indicates double mixing).

subsides faster than the radiative increase of $p^{*}$, then $P$ can reach relatively large negative values (figure $4 \mathrm{c}$, $4 d)$. Figure $4(a, b)$ which is representative of the disturbed period shows smaller negative values of $P$ as convective mixing dominates during this period. The inversion top can also be characterised by the minimum $P$.

The $\left(\theta_{e}, q\right)$ plots given in figure $5(\mathrm{a}-\mathrm{d})$ show double mixing line structures with a small $q$ reversal at around $879 \mathrm{~m}, 1660 \mathrm{~m}, 870 \mathrm{~m}$ and $512 \mathrm{~m}$ (represented in figure) respectively and similarly at the top of the CBL at $2585 \mathrm{~m}, 1761 \mathrm{~m}, 2167 \mathrm{~m}$ and $3256 \mathrm{~m}$ (represented in figure) respectively during the disturbed period. The existence of this double mixing line structure is difficult to be explained, but it could be spe- culated that differential horizontal advection of boundary layers could be the possibility. At the top of the CBL $q$ minimum is observed. Such well mixed layer where convective mixing plays a dominant role is not observed during the undisturbed period (figure 6(a-d)). As suggested by Betts and Albrecht (1987), the precipitation-evaporation processes are responsible for this double mixed layer structure, once the CBL reaches a sufficient depth.

The instability in the atmosphere during the disturbed period can also be viewed from the $\partial S_{e s} / \partial z$ profile figure $7(\mathrm{a}, \mathrm{b})$. It is noticed that during the disturbed period when convective activity is prominent the gradient $\partial S_{e s} / \partial z$, tends to attain a negative value. While in calm conditions, during the undisturbed 

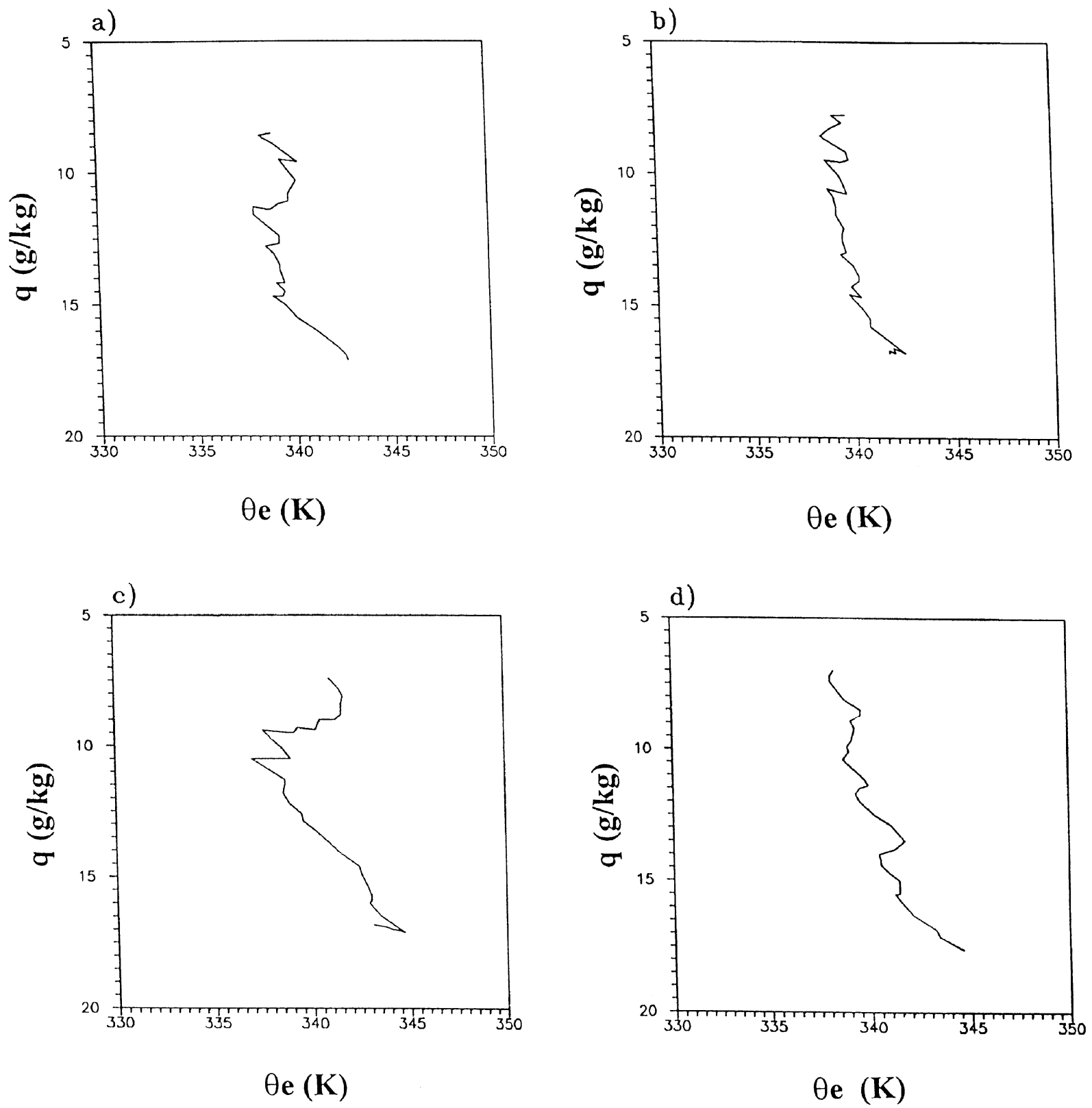

Figure 6. Plot of $\theta_{e}$ against $q$. During undisturbed period (a) 03-11-1998, 2030 IST; (b) 04-11-1998. 0700 IST; (c) 04-11-1998, 1400 IST; (d) 05-11-1998, 0615 IST.

period (figure $7 \mathrm{c}, \mathrm{d}$ ), this gradient tends to be positive characterizing stable atmosphere.

The daily mean of the components of the Oceanic Heat Budget such as $Q_{S}, Q_{B}, Q_{H}, Q_{E}$ and $Q_{N}$, the total cloud amount, wind speed, and sea minus air temperature is given in table 2. On 30th October 1998, the average surface winds observed, are found to be of the order of $8.5 \mathrm{~ms}^{-1}$. On this day, the mean latent heat flux is found to be equal to $222 \mathrm{Wm}^{-2}$, which is higher than that computed during the undisturbed period. This could also be one of the reasons for higher MBLH during this period. The synoptic observation stated the presence of low (cumulus) clouds during the disturbed period, when it rained. This observation was confirmed by the analysis of the satellite pictures (Kalsi 1999). While, during the undisturbed period such cloudy conditions were not observed to bring about any significant weather phenomenon. The sea minus air temperature is always positive indicating that throughout the cruise the sea is found to be warmer than the overlying atmosphere. A maximum difference of $2.0^{\circ} \mathrm{C}$ is observed on 31st October 1998 and a minimum of $0.86^{\circ} \mathrm{C}$ is seen on 5 th November 1998. It is also observed that the short-wave flux obtained from the aforementioned empirical is in good agreement with the observations (Report DST 1999). 

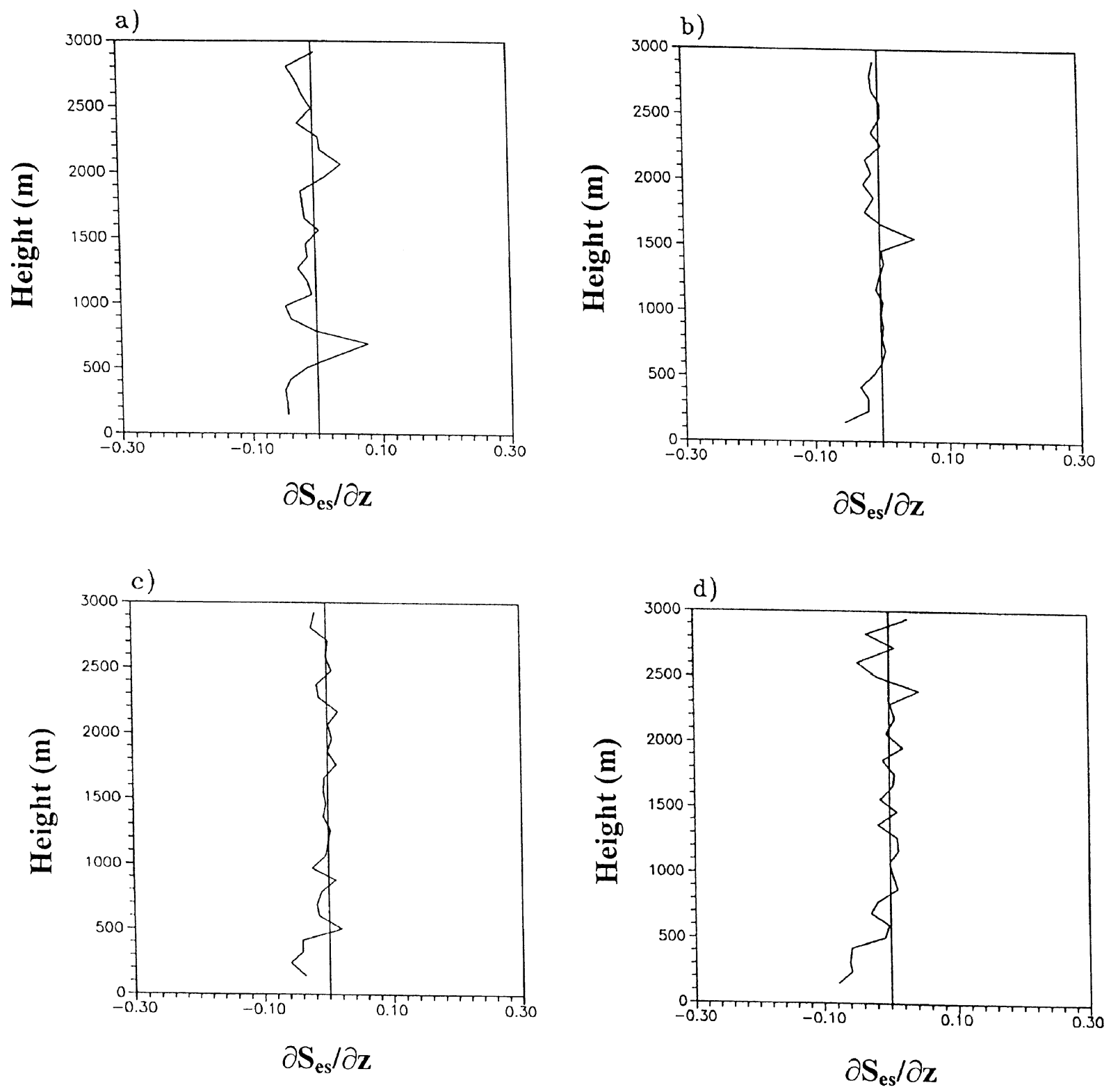

Figure 7. Plot of $\partial S_{e s} / \partial z$ against height. During disturbed period (a) 31-10-1998, 0700 IST; (b) 01-11-1998, 1430 IST. During undisturbed period (c) 04-11-1998, 0700 IST; (d) 05-11-1998, 1400 IST.

Table 2. Daily mean of the surface meteorological parameters and the oceanic heat budget components.

\begin{tabular}{lccccrrrr}
\hline Date & $\begin{array}{c}\text { Total cloud } \\
\text { amount (Octa) }\end{array}$ & $\begin{array}{c}\text { Wind speed } \\
\left(\mathrm{ms}^{1}\right)\end{array}$ & $\begin{array}{c}\text { Sea minus } \\
\text { air temp. }\left({ }^{\circ} \mathrm{C}\right)\end{array}$ & $Q_{S}$ & $Q_{B}$ & $Q_{H}$ & $Q_{E}$ & $Q_{N}$ \\
\hline $30-10-98$ & 6.3 & 8.5 & 1.1 & 204 & 35 & 18 & 222 \\
$31-10-98$ & 6.8 & 3.8 & 2.0 & 179 & 35 & 14 & 95 \\
$02-11-98$ & 6.9 & 3.9 & 1.8 & 205 & 35 & 13 & 99 \\
$03-11-98$ & 5.6 & 2.8 & 1.8 & 207 & 39 & 11 & 74 \\
$05-11-98$ & 5.7 & 8.1 & 0.8 & 268 & 37 & 13 & 136 \\
\hline
\end{tabular}

\section{Conclusions}

The conserved variable analysis is found to be useful in the study of the thermodynamic structure of the convective boundary layer. For shallow CBLs during the undisturbed period, a single mixing line is seen through the cloud and inversion layers. However, deeper CBLs, all of them show double mixing lines. This could be due to the precipitation-evaporation processes, which are responsible for the double mixed 
layer structure once the CBL (and the deepest clouds in it) reaches a sufficient depth. As suggested by Betts and Albrecht (1987), it can be speculated that a $q$ and $\theta_{e}$ reversal within the CBL could be maintained by penetrative downdrafts driven by evaporation of precipitation.

The soundings show a $\theta_{e}$ and $P$ minimum, $\theta_{e s}$ maximum and local $q$ minimum at the CBL top. The CBL top thus appears on a $\theta_{e}-q$ diagram as a marked kink, which marks the top of the layer that is thermodynamically coupled to the surface.

The net oceanic heat budget is found to be lower during the disturbed period than that in the undisturbed period. This is due to the reduction in the solar radiation flux because of the overcast condition. Also during this period the latent heat flux is higher due to the high surface wind speeds and the related instability in the surface marine boundary layer.

\section{Acknowledgement}

We express our gratitude to the scientific team on board ORV Sagar Kanya for their participation and valuable help in carrying out the observations. We thank the Department of Science and Technology (DST) for funding this field experiment. Our sincere appreciation is also due to the Indian Institute of Science (IISc), Bangalore, Indian Meteorological Department (IMD) and National Institute of Oceanography, Goa for providing the necessary data sets for this study.

\section{References}

Albrecht B A, Ramanathan V and Boville B A 1986 Meteorology over the Tropical Oceans, (ed) D. B. Shaw Roy. Meteorol Soc. 73-104.

Atwater M A and Ball J T 1981 Mon. Weather Rev. 109878 888

Betts A K 1982 J. Atmos. Sciences 39 1484-1505.

Betts A K and Albrecht Bruce A 1987 J. Atmos. Sciences 44, 83-99.

Betts A K 1986 Q. J. Roy. Meteorol. Soc. 112 677-691.

Betts A K 1985 J. Atmos. Sciences 42, 2751-2763.

Betts A K and Miller M J 1986 Q. J. Roy. Meteorol. Soc. 112 693-701.

Bunker A F 1965 Interaction of the summer monsoon air with the Arabian Sea; Proc. Symp. on Met. Results, IIOE, Bombay, 3-16.

Girduk G V and Malevaski-Holekyich S P 1973 Trudi Main Geophysical Observations, Leningrad 297 124-132

Jambunathan R and Ramamurty K 1975 Indian J. Met. Geophys. 25 377-410.

Kalsi S R Workshop on Bay of Bengal and Monsoon Experiment (BOBMEX) Pilot Study Results, 19 April 1999, IIT Delhi, India

Kondo J and Mirua A 1985 Surface heat budget of the SouthWestern Pacific for May 1979; J. Meteorol. Soc. Japan. 63 633-646.

Mohanty U C and Mohan Kumar 1990 Atmospheric Environment 24A No. 4 823-828.

Mohanty U C and Dube S K 1981 Mausam 32 315-320.

Mohanty U C and Mohan Kumar 1998 Indian J. Marine Sciences 27 60-65.

Pant M C 1978 Indian J. Hydrol. Geophys. 29 p 88.

Ramanathan Y 1978 Indian J. Meteor. Geophys. 29, 643-654.

Sam N V, Satyanarayana A N V and Mohanty U C A Study on Certain Characteristic Features of Air-Sea Exchange Processes and Marine Boundary Layer with BOBMEX-98 Pilot Experiment Data Sets, Report, DST, January 1999. 